\title{
Comprehensive compensation method for thermal error of a vertical drilling center
}

\begin{tabular}{|c|c|}
\hline Journal: & Transactions of the Canadian Society for Mechanical Engineering \\
\hline Manuscript ID & TCSME-2018-0079.R1 \\
\hline Manuscript Type: & Article \\
\hline $\begin{array}{l}\text { Date Submitted by the } \\
\text { Author: }\end{array}$ & 11-Jun-2018 \\
\hline Complete List of Authors: & $\begin{array}{l}\text { Kang, ChengMing; Northeastern University, Mechanical Engineering and } \\
\text { Automation } \\
\text { Zhao, Chunyu; Northeastern University, Mechanical Engineering and } \\
\text { Automation } \\
\text { Liu, Kuo; Dalian University of Technology, Mechanical Engineering and } \\
\text { Automation } \\
\text { Li, TieJun; Shenyang University of Chemical Technology, Mechanical and } \\
\text { Automation } \\
\text { Yang, Bo; Northeastern University, Mechanical Engineering and } \\
\text { Automation }\end{array}$ \\
\hline Keywords: & $\begin{array}{l}\text { Screw shaft, Spindle, Comprehensive error compensation method, } \\
\text { Robust }\end{array}$ \\
\hline $\begin{array}{r}\text { Is the invited manuscript for } \\
\text { consideration in a Special } \\
\text { Issue? : }\end{array}$ & Not applicable (regular submission) \\
\hline
\end{tabular}




\section{Comprehensive compensation method for thermal error of a}

\section{vertical drilling center}

ChengMing Kang ${ }^{1}$, ChunYu Zhao ${ }^{1}$, Kuo Liu ${ }^{2}$, TieJun $\mathrm{Li}^{1}$, Bo Yang ${ }^{1}$

${ }^{1}$ School of Mechanical \& Automation, Northeastern University, Shenyang 110819, China.

${ }^{2}$ School of Mechanical \& Automation, Dalian University of Technology, Dalian 116024, China.

Corresponding author: ChengMing Kang, E-mail: 578501944@qq.com

ChunYu Zhao: chyzhao@mail.neu.edu.cn

Kuo Liu:liukuo@dlut.edu.cn

TieJun Li: 116053994@qq.com

Bo Yang:yangbo5326@gmail.com 
Abstract To eliminate the influence of thermally induced error of machine tool on the machining accuracy, a comprehensive error compensation method for the thermal displacement of the screw shaft and spindle is put forward. Based on heat transfer mechanism and experimental analysis, the model of the screw thermal expansion error is built. Similarly, the modeling of the spindle thermal growth depending on speed variations is proposed. Then, the thermal tests for studying thermal behavior of the spindle and screw axis are carried out on the vertical drilling center TC500R.Finally, the compensation effect of the robust model is validated via experimental test and machining. The experimental results show that the thermal displacement variations are controlled within $2 \mu \mathrm{m}$ when the compensation system is activated. The suggested model can achieve high accuracy and well applicability of different moving state. The machining results indicate that the dimensional accuracy of the workpiece is significantly improved after implementation of the compensation. The feasibility of the thermal error compensation system can satisfy in application on the drilling operation.

Keywords Screw shaft, Spindle, Comprehensive error compensation method, Robust 


\section{Introduction}

To supply productions with fine quality and high precision, the errors in machining process should be reduced. Errors that affect accuracy of machine tool are classified as geometric errors of machine components, errors induced by heat, errors induced by cutting force. Among various error sources, thermal errors are a major contributor, accounting for as much as $40-70 \%$ of the total errors (e.g., Bryan 1990; Ramesh et al. 2000; Mayr et al. 2012; Yang et al. 2015). The thermal errors of the machine tool are a time-varying and nonlinear process.

In general, manufacturers adopt primarily two strategies to minimize thermal errors: error avoidance and error compensation (Ni 1997 and Yang 1998). The purpose of former method is trying to reduce the thermal deformation of machine tools during the design or assembling phase of machine tools, such as adopting cooling system, using symmetric structure and thermally insensitive materials (Creighton et al. 2010).Although error avoidance could control machine tool errors to some degree, production costs will increase dramatically. Hence, error avoidance is not widely or cost-effective used method for enhancing machine accuracy. While the later method is a "soft technique" that tends to create an opposite error to eliminate the original thermal error (Han et al.2013). The 
thermal error compensation method has advantage of diverse applications and a lower cost over other.

In light of all factors contributing to thermal deformation of machine tool, thermal errors of screw shaft and spindle play a significant role. The source of spindle thermal growth is heat generation caused by bearings rotation, motor heating, and ambient temperature variation. Similarly, the friction of nut and screw, the rotation friction of bearings, and the effect of ambient temperature are major sources of screw thermal expansion. The comprehensive thermal error of machine tools is induced from the superposition of the screw thermal expansion error (TEE) and spindle thermal growth error (TGE). Thus, the use of error compensation method to eliminate these two types of thermal error is the subject of current research.

Many scholars have applied mathematical method for thermal error modeling by directly mapping the temperature data of the critical machine elements to the thermal error. These mathematical modeling techniques include artificial neural network (Zhang and Yang 2011; Jin and Wang 2012), multiple linear regression (Pajor and Zapłata 2011; Lei and Rui 2012), gray model (e.g., Yan and Yang 2009; Zhang et al.2012), support vector machine (e.g., Ramesh et al.2002; Lin et al.2009), time series model (e.g., Li et al. 2006; Shu et al. 2012), and thermal mode (Zhu et al. 2008). C.W. Wu et al. (2011) presented a method based on multivariate linear regression to implement the screw axial expansion compensation. Huang et al. (2014) introduced a combined thermal error model 
for compensating the radial thermal drift of the spindle, and genetic algorithm (GA) is used to optimize initial weights and thresholds of neural network (BP).Using this method, the average compensation rate is improved from $89.03 \%$ to $93.155 \%$ of GA BP model. Jun Yang et al. (2015) built a spindle thermal error model using least squares support vector machine (LS-SVM). The aforementioned compensation methods obtain good results, however, these methods suffer from following problem:

1. Poor robustness. Most of the aforementioned compensation methods are data-driven model (DDM), which require sufficient data to represent the input-output relationships associated with the process. The primary disadvantage of DDM is that when the moving state of a machine tool in actual machining differs from that of the modeling tests, the prediction results will get worse, especially multiple linear regression method.

2. Condition limitation. Many methods only function in particular conditions. For instance, artificial neural network method has a worse prediction effect if incomplete input and output information is used. Time series method needs test data under various speeds to improve accuracy of error model.

3. Position limitation. The machine structure has the limited space to set up the equipment for the thermal error test. For example, the sensors cannot directly measure the temperatures of ball screw owing to the moving nut.

4. Economy and reliability. The aforementioned compensation methods require 
numerous sensors to achieve higher prediction accuracy, which costs expensively. Moreover, the sensors are needed to protect from coolant and chips to maintain system reliability.

To develop a practical model with high accuracy and strong robustness, a novel modeling method for the comprehensive thermal displacement of the screw axis and spindle is proposed in this paper. The real-time mathematics model of the screw and spindle thermal deformation is established though mechanism and thermal analysis. Then, the thermal characteristics tests of the screw axis and spindle are designed and conduced on a drilling machine, the results of which are used to evaluate the thermal model. Finally, experimental tests and machining are performed for further verification of the effectiveness of the error modeling, measurement, and compensation method.

\section{Thermal error model establish and result analysis}

\subsection{Combination errors of spindle and servo shaft}

Figure 1 shows the comprehensive thermal displacement of the spindle and screw shaft. It could be observed from Fig.1 that the thermal error of machine tool is influenced by both TGE and TEE terms; when the directions of the spindle thermal growth and screw thermal expansion error are the same, the axial thermal error of the machine tool will aggravate. Hence, these two kinds of thermal errors should be compensated together.

The comprehensive thermal displacement is a function not only of spindle speed, but also of screw shaft position. The comprehensive thermal displacement model of spindle 
and screw shaft can be depicted as follows:

$$
E_{\text {sup }}\left(\mathrm{z}_{i}, S_{i}\right)=E_{c s e}+E_{c f e}
$$

The modeling process for thermal displacement of screw shaft and spindle is introduced respectively to section 2.2 and 2.3.

\subsection{Modeling of screw axis}

In general, there exist sources of heat generation inducing thermal deformation of the ball screw system, which influences the positioning precision of a machine tool. The thermal deformation of the screw axis is related to the energy that heats the one. Heat generation caused by the friction is dependent upon feed rate, which leads to the thermal extension of the screw ( $\mathrm{Li}$ et al.2014). The stroke range of a screw is short and its movement intermittent during the actual machining. The feed frequency is utilized in the real-time thermal extension determination. Meanwhile, a part of the produced heat flows out the screw via natural convection, which causes the screw to contract. The thermal expansion error model has the formulation as

$$
\zeta_{\text {screw }}(T)=\zeta_{\text {screw }}(T-1)+Q_{\mathrm{e}}(T)-Q_{\mathrm{r}}(T)
$$

From Fig.2, it is not difficult to find that a screw displacement variation trend is in keeping with the law of the natural exponential function. An exponential growth model is defined to describe the thermal extension of a screw by using the average feed speed and feed frequency

$$
Q_{\mathrm{e}}(T)=\lambda \cdot\left[z_{i} \cdot V(T)\right]^{r} \cdot[C(T)]^{s}
$$


When the nut moves along its whole stroke, the average feed rate and feed frequency is determined by the positional change of the $Z$-axis. The average feed rate calculation is given using equation (4):

$$
V(T)=\left[\left|\frac{z_{1}-z_{0}}{\Delta T}\right|+\left|\frac{z_{2}-z_{1}}{\Delta T}\right|+\mathrm{K}+\left|\frac{z_{i}-z_{i-1}}{\Delta T}\right|+\mathrm{K}+\left|\frac{z_{N}-z_{N-1}}{\Delta T}\right|\right] / K
$$

The feed frequency can be written as:

$$
C(T)=\frac{K}{N}
$$

Following Figure 2 shows the positioning errors of the screw shaft obey a stable exponential decrease during cooldown phase. An exponential model can be obtained to describe contraction of a screw due to heat dissipation

$$
Q_{\mathrm{r}}(T)=\kappa \cdot\left[\zeta_{\text {screw }}(T-1)\right]^{h}
$$

As the ball screw experiences the natural cooling, only friction heat is dissipated to the open air, which results in a screw shrinkage (as shown in Figure 3). Though the Eq. (2) transition, the thermal characteristic of the screw shaft during the free cooling process

$$
\zeta_{\text {screw }}(T)=\zeta_{\text {screw }}\left(t_{a}\right)-\left(Q_{\mathrm{r}}\left(t_{1}\right)+Q_{\mathrm{r}}\left(t_{2}\right)+\mathrm{L}+Q_{\mathrm{r}}\left(t_{j}\right)\right)
$$

where, $t_{j}(j=1,2, \mathrm{~K}, \mathrm{~m})$ is the data collection time during screw experiment.

Figure 2 presents the screw thermal error variation under the different positions of Z-axis; it is not only related to the mean feed rate and feed frequency but also affected the axis position. Therefore, an exponential model with respect to the axis position is employed to describe the position displacement of a screw. 
$E_{c f e}(T)=z^{\tau} \cdot \zeta_{\text {screw }}(T)$

where $z$ is the vertical distance between the displacement sensor and the end of the spindle, which is depicted in Fig.1.

Although the model proposed in Section 2.2, many unknown parameters need to be determined. Tests to identify these parameters is described in Section 3.1 using the data shown in Fig.3.The predicted screw curve is obtained though fitting the tested screw data. The method to match the two values is though the least squares of the differences between them. The optimization algorithm is written the program in MATLAB software, and optimum objective function is defined as follows

$$
\min [F(\lambda, \kappa, r, s, h, \tau)]=\sum_{u=1}^{U} \sum_{v=1}^{V}\left(E_{t f e}(u, T)-E_{c f e}(u, T)\right)^{2}
$$

where $E_{t f e}(u, T)$ denotes the experimental data of the $u$ th test point at the $v$ th test; $E_{c f e}(u, T)$ denotes the estimated error of the $u$ th test point at the $v$ th test.

Figure 4 presents that comparison of measured and simulated value of thermal deformation of the screw shaft. It could be observed that the fitting curve can well match measured errors during warmup and cooldown phase. Therefore, the accuracy of the exponential model is suitable for its use in practical application.

\subsection{Modeling of spindle}

Thermal error induced by spindle composes of radial thermal drift error (RTDE) and axial thermal growth error (ATGE).In this paper, spindle is assumed to be rigid and not 
bend, so the radial thermal error of spindle can be ignore. Figure 5 depicts the thermal characteristics of the spindle are depending on spindle speed. Because of this, thermal growth model of the spindle is one in which the spindle speed as an input variable is considered. The expression thermal growth of the spindle during the heating process is described by equation (10).

$\delta_{\text {spindle }}(T)=\delta_{\text {spindle }}(T-1)+Q_{\text {spindle }}(T)-q_{\text {spindle }}(T)$

To eliminate the effect of variation with time in the spindle speed, the meaning speed calculation could be established as follows:

$$
S(T)=\frac{S_{1}}{N}+\frac{S_{2}}{N}+\mathrm{K}+\frac{S_{i}}{N}, i=1,2, \mathrm{~K}, N
$$

When the spindle is rotated, heat generation at representative portions causes the spindle to thermally deform. The results from the thermal characterization tests of the spindle at the various rotation speeds are used to develop a spindle thermal extension that is exponential in nature, as performed in equation (12) and similar to one proposed in (Kim et al.2004)

$Q_{\text {spindle }}(T)=\alpha \cdot[S(T)]^{w}$

During machining process, heat transfers from the spindle into the ambient air. The contraction of the spindle due to heat dissipation is calculated as follows:

$q_{\text {spindle }}(T)=\eta \cdot\left(\delta_{\text {spindle }}(T-1)\right)^{\varepsilon}$

The spindle is being warmed until interrupted to cool freely. No more heat generated flows into spindle, and the residual friction heat would be gradually dissipated into the 
ambient surrounding. According to Eq. (10), thermal distortion model of a spindle when cooled is obtained as follows

$\delta_{\text {spindle }}(T)=\delta_{\text {spindle }}\left(t_{b}\right)-\left(q_{\text {spindle }}\left(t_{1}\right)+q_{\text {spindle }}\left(t_{2}\right)+\mathrm{L}+q_{\text {spindle }}\left(t_{k}\right)\right)$

where $t_{k}$ is cool time, and $t_{k}=n \cdot \Delta t, k=1,2, \ldots, n$.

The relative positional deviation between the spindle and workpiece is induced by thermal deformation of the spindle, which can be determined by the measured screw data. Therefore, the spindle thermal growth could be developed as the screw position displacement. The thermal growth of a spindle related to the axis location and thermal characteristic is represented by Eq. (15)

$E_{\text {cse }}(T)=z^{\tau} \cdot \delta_{\text {spindle }}(T)$

The aforementioned parameters are identified by minimizing the differences between the results of the test curve and the estimated values of the model curve. The optimum objective function can be obtained as follows:

$$
\min [F(\alpha, \eta, w, \varepsilon, \tau)]=\sum_{T=1}^{K}\left(E_{\mathrm{tse}}(T)-E_{\mathrm{cse}}(T)\right)^{2}
$$

where $E_{\text {tse }}$ is the tested thermal error.

Figure 6 presents the modeling results for the spindle thermal growth under various rotating speed. It could be seen from Figure. 6 that the predicted values gotten by using the error model agrees with that of experiment during the operation. The prediction effect of the model is proved well. 


\section{Testing procedure}

To investigate thermal deformation of the spindle and ball screw shaft, experiments are carried on a vertical drilling center TC500R. The spindle is drove by belt and spindle speeds up to $20000 \mathrm{r} / \mathrm{min}$. The feed drive system chooses half-closed-loop control and the maximum feed rate is $48 \mathrm{~m} / \mathrm{min}$; the up end of the ball screw is fixed, and down end of it is supporting. Besides, the control system of the machine tool adopts FANUC $0 i$-Mate.

\subsection{Screw axis test}

The thermally induced positioning error of the ball screw is performed using a laser interferometer XL80 manufactured by Renishaw Company, UK. It should be noted that the parameter "expansion compensation of material" of Renishaw software would be set as $20^{\circ} \mathrm{C}$ to cancel ambient temperature compensation function of the software. The real-time position of $Z$-axis is collected by the computer with Visual $\mathrm{C}++$ developing FOCUS program at a sampling interval of 50 millisecond.

To study thermal change in active length of the ball screw, the reference origin of the machine is set to be the starting point for this measurement and positioning errors are measured every $70 \mathrm{~mm}$ in the entire stroke. The test procedure is given as follows:

1. Let the $Z$-axis move up $150 \mathrm{~mm}$ as the commanded position for this measurement.

2. Move the $Z$-axis in the stroke range of $0-280 \mathrm{~mm}$ for $10 \mathrm{~min}$ at the feed rate of 10000 $\mathrm{mm} / \mathrm{min}$.

3. Stop moving and test the positioning error of $Z$-axis. 
4. Repeat steps (2) and (3) for four times.

5. Let the $Z$-axis stop at $10 \mathrm{~mm}$ position for free cooling. The positioning error is measured at interval 10min for four times.

Figure 3 shows that the test results of $Z$-axis. It could be observed from Figure 3 that that the position displacement of the ball screw at all the test points varies with time, and the positioning error curves change little in shape.

Similarly, the error tests are conducted under $z=50 \mathrm{~mm}$ in the same manner.

\subsection{Spindle test}

The thermal growth of the spindle is tested using a spindle error analyzer CPL290 manufactured by Lion Precision Corporation, USA. The displacement sensors are fixed on the worktable via the fixture and aim at the precision ball motion, as shown in Fig.7.The computer with Visual $\mathrm{C}++$ developing FOCUS program is utilized to collect the real-time rotating speed at a sampling period of 50 millisecond.

The spindle whose thermal characteristic is assessed at the speeds of 500 and 1500 $\mathrm{r} / \mathrm{min}$, respectively. In each test, the spindle rotates at a preset speed for 2.5 hours and then remains stop for 3.5 hours. The sample period for spindle thermal error is set at $10 \mathrm{~s}$, and the obtained results are plotted in Fig.5.It could be observed from Fig.5 that the higher rotating speed are and the higher thermal growths are. In contrast, it could be observed from error diagram that error values appear to be positive first, which is interpreted that test bar moves downwards. But as heat generation and heat dissipation 
reach thermal equilibrium, the increase of the spindle elongation slows down. When spindle is suspended, spindle starts to shrink by giving off its heat.

\section{Compensation strategy and verification}

\subsection{Compensation strategy}

In this section, the effect of the thermal compensation will be validated by the laser interferometer XL80.For this, the real-time spindle speed and screw position need be read from $\mathrm{CNC}$ though the Ethernet cable, and the real-time compensation values need be input to the $Z$-axis of the vertical drilling center. The external mechanical coordinate offset (EMCO) is used to write the offset values for FANUC 0i-mate CNC (FANUC (2003)).The schematic diagram of real-time thermal error compensation is described in Fig.8.

The thermal error compensation system is developed based on EMCO, which is made up of the hardware and software platforms. The hardware platform is composed of the error acquisition unit and thermal compensator; the modeling, data acquisition, $\mathrm{CNC}$ communication, and real-time thermal error compensation are implemented in the software platform. The software interface of real-time thermal error compensation is shown in Fig.9.

\subsection{Experiment verification}

To verify the effectiveness of the modeling for comprehensive thermal growth of the ball screw shaft and spindle, compensation experiments are performed on the TC500R. The 
photograph of the experimental device is depicted in Figure 10, where Figure 10 shows the spectroscope is installed at the end of the worktable and the reflector is mounted on the spindle; the laser interferometer XL80 records the relative error of spindle and worktable in Z-direction.

The procedure of experimental test is presented as follows: (1) recorded the tool position to as set axis position at this measurement. (2) Let $Z$-axis and spindle move according to the path listed in Table1. (3) Stop and measure the positioning error of $Z$-axis every 10 min before and after compensation.

The experimental results are shown in Figure. 11.

In Figure. 11, "N" is the errors before compensation and " $\mathrm{Y}$ " is the residual errors after compensation.

Figure. 11 shows that comprehensive thermally induced errors of the ball screw and spindle after compensation are greatly decreased from more than $25 \mu \mathrm{m}$ to $2 \mu \mathrm{m}$ or less, which demonstrates that the predicted accuracy of the presented model is high. Note that the residual errors with compensation are almost little, even changing the motion information according to the parameters listed in Table1.Thus, the strong robustness of the comprehensive error model is evaluated.

\subsection{Machining verification}

Machining with and without compensation is conducted to validate the feasibility of the compensation system, as shown in Fig.13. According to ISO10791-7 and Taguchi 
method (Ramazan et al.2013), several test specimens with and without compensation are milled the upper surface of a rectangular plate and are sequenced in Figure 12. The material of rectangular workpiece is the steel and its size is $150 \mathrm{~mm} \times 115 \mathrm{~mm} \times 30 \mathrm{~mm}$. The machining procedure is performed as follows:

1. Let a $\varphi 140$-disc milling cutter mill the upper surface to guarantee side surface finished and flatness, as shown in Fig.13 (a).

2. Hole1 is milled with a milling depth of $5 \mu \mathrm{m}$ using a $\varphi 12$-disc 4-edge milling cutter. Open compensator and Hole2 is drilled with the same depth as Hole 1.

3. Move the worktable to the left side. Let $Z$-axis and spindle run according to the path presented in Fig.14. The one hole is drilled without compensation; the other hole is drilled with compensation.

(1) Repeat step (3) for three times until holes 5-10 is machined.

(2) Warm up stop and move the worktable $25 \mathrm{~mm}$ along $X$-direction. 15-mm-depth Hole11 is drilled without compensation. Open compensator and drill Hole12 to the right side. The similar process is conducted in Fig.14 under the same manner.

The workpieces machined pre and post-compensation are shown in Figure13 (b). Fig.13 (b) shows that the micron-scale errors of $Z$-axis of a vertical drilling center are easily observed by the naked eye. Moreover, the specimens with compensation have well consistency at ring-shaped profile. The dimensional accuracy is further examined for the holes 13-20 under machining with and without the activation of thermal error 
compensation system, as listed in Tables 2. As is shown, the size variations of the machined holes are reduced from $10 \mu \mathrm{m}$ (before compensation) to $2 \mu \mathrm{m}$ (after compensation). The accuracy of workpieces is improved by above $70 \%$. The results verify that the feasibility of real-time compensation system for minimizing thermally induced errors in actual machining applications.

\section{Conclusions}

This article proposes a comprehensive compensation method for thermally induced errors of the screw axis and spindle. The compensation effects are validated by both experiment and machining. The advantages of compensation method can be stressed as follows:

1. The comprehensive thermal error model of ball screw and spindle established in this article could achieve a good compensation performance in terms of robustness and accuracy.

2. The comprehensive thermal errors of ball screw and spindle is offset together. Experimental results reveal that accuracy stability of the proposed model could be achieved even if movement of the machine tool changed irregularly. Machining results reveal that the dimensional accuracy is decreased from $10 \mu \mathrm{m}$ to $2 \mu \mathrm{m}$ under the activating compensation system. The feasibility of the compensation system can satisfy in actual application in the drilling operation.

3. The comprehensive compensation method is cost-effective that only uses a displacement sensor to function. 
4. The test efficiency for thermal errors of ball screw and spindle is high, as first-transition displacements can be predicted for ball screw and spindle.

Therefore, the compensation method can be widely applied to the CNC machine tools in no temperature-controlled workshop.

\section{Acknowledgements}

This work was supported by the National Natural Foundation of China (Grant No. 51775094).

\section{Reference}

Bryan, J. 1990. International status of thermal error research. J. CIRP Ann. Manuf. Technol.39 (2):645-656.

Çakıroğlu, R., and Acır, A. 2013. Optimization of cutting parameters on drill bit temperature in drilling by Taguchi method. J. Measurement .46 (9): 3525-3531. https://doi.org/10.1016/j.measurement.2013.06.046.

Creighton, E., Honegger, A., Tulsian, A., and Mukhopadhyay, D.2010.Analysis of thermal errors in a high-speed micro-milling spindle. J. Mach. Tools. Manuf.50 (4):386-393. https://doi.org/10.1016/j.ijmachtools.2009.11.002.

FANUC. 2003. FOCAS1: FANUC Open CNC API Specifications version 1-FOCAS1/Ethernet CNC/PMC Data window library.

Han, ZY. , Jin, HY. , Liu, YL. , and Fu, HY. 2013. A review of geometric error modeling and error detection for CNC machine tool.J.Appl.Mech.Mater.303-306:627-631. https://doi.10.4028/www.scientific.net/AMM.303-306.627. 
Huang, YQ. , Zhang, J., Xu, L., and Tian, LJ. 2014. Thermal error modeling by integrating GA and BP algorithms for the high-speed spindle. J. Adv. Manuf. Technol. 71:1669-1675. https://doi.10.1007/s00170-014-6535-7.

ISO10791-7.1998.Machine tools-test conditions for machining centers-Part7: Accuracy of a finished test piece.

Jin, ZF. , and Wang, P. 2012. Neural network-based thermal error modeling in ball screw. J. Modular Mach .Tool Autom. Manuf. Tech. 1:67-70.

Kim K. and Chung, S. 2004. Compensatory control of thermal errors for high-speed machine tools. Pro I Mech E. Part B: J. Eng. Manuf .218: 913-924.

Lei, CL., and Rui, ZY. 2012. Thermal error modeling and forecasting based on multivariate autoregressive model for motorized spindle. J .Mech .Sci .Technol. Aerosp. Eng. 20(2):1526-1529.

Li, YX., Tong, HC. Cao, HT. Zhang, HT., and Yang, JG. 2006. Application of time series analysis to thermal error modeling on NC machine tool. J .Sichuan Univ .38(2): 74-78.

Li, Z., Fan, K. Yang, J. , and Zhang, Y.2014.Time-varying positioning error modeling and compensation for ball screw systems based on simulation and experimental $\begin{array}{lllll}\text { analysis. } & \text { J. Adv. }\end{array}$ https://doi.org/10.1007/s00170-014-5865-9.

Lin, WQ., Fu, JZ., Chen, ZC., and Xu, Y.Z. 2009. Modeling of NC Machine Tool Thermal Error Based on Adaptive Best-fitting WLS-SVM .J. Mech Eng.45 (3):130-135. https://doi.10.3901/JME.2009.03.178.

Mayr, J., Jedrzejewwski, J., and Uhlmann, E. 2012.Thermal issues in machine tools. CIRP Ann. Manuf .Technol. 61:771-791. 
Ni, J.1997.CNC machine accuracy enhancement through real-time error compensation. J. Manuf. Sci. E-T .ASME .119:717-725.

Pajor, M., and Zapłata, J. 2011 .Compensation of thermal deformations of the feed screw in a CNC machine tool. J .Adv. Manuf. Technol. 35(4):9-17.

Ramesh, R., Mannan, M.A., and Poo, A-N. 2000 .Error compensation in machine tools-a review part II: thermal errors. J .Mach. Tools Manuf. 40:1257-1284.

Ramesh, R., Mannan, M.A, and Poo, A.N. 2002.Support vector machines model for classification of thermal error in machine tools. J. Adv. Manuf. Technol. 20(2): 114-120. https://doi.10.1007/s001700200132

Shu, QL., Li, YL. , and Lv, YS. 2012.Application of time series analysis to thermal error modeling on NC micro-grinder. J .Mod. Mach. Tool Auto. Manuf. Tech. $12: 30-32$.

Wu, CW., Tang, CH., Feng, CF., and Shao, YS. 2011. Thermal error compensation method for machine center. J .Adv. Manuf. Technol. 59:681-689. https://doi.10.1007/s00170-011-3533-X.

Yan, JY. , and Yang, JG. 2009. Application of synthetic grey correlation theory on thermal point optimization for machine tool thermal error compensation. J. Adv. Manuf. Technol. 43(11-12):1124-1132. https://doi.org/10.1007/s00170-008-1791-z.

Yang, J. 1998. Error synthetic compensation technique and application for NC machine tools. Shanghai Jiao Tong University, Shanghai.

Yang, J., Shi, H., Feng, B., Zhao, L., Ma, C., and Mei, XS. 2015. Thermal error modeling and compensation for a high-speed motorized spindle. J. Adv. Manuf. Technol. 77: 1005-1017. https://doi.org/10.1007/s00170-014-6535-7 
Zhang, Y., and Yang, JG. 2011. Modeling for machine tool thermal error based on Grey model preprocessing neural network. J.Mech.Eng. 47(7):134-139. https://doi.10.3901/JME.2011.07.134

Zhang, Y., Yang, JG., and Jiang, H. 2012. Machine tool thermal error modeling and prediction by grey neural network. J. Adv. Manuf. Technol. 31(9):1065-1072. https://doi.10.1007/s00170-011-3564-3.

Zhu, J., Ni, J., and Shih, AJ. 2008. Robust machine tool thermal error modeling through thermal mode concept. J .Manuf. Sci. Eng.130:0610061-0610069. https://doi.10.1115/1.2976148.

Fig.1. Superposition of thermally induced errors of the spindle and ball screw

Fig.2. Positioning errors of ball screw under different axis positions

Fig.3.Positioning errors of ball screw under different temperature conditions

(a) Warm-up phase. (b)Natural cooldown phase

Fig.4. Comparison between measured and predicted positioning errors

(a) Warm-up phase. (b)Natural cooldown phase

Fig.5.Axial thermal error for various rotating speeds

Fig.6. Fitting results of estimated model under different temperature conditions

Fig.7. Spindle thermal characteristics test platform 
Fig.8.The schematic diagram of thermal error compensation

Fig.9. Interface of thermal compensation software

Fig.10. Compensation experimental equipment

Fig.11.Compensation results under different experimental conditions.

Fig.12. Position of the holes in the steel plate

Fig.13.Machining process of test samples: (a) Milling flat. (b) Drilling holes

Fig.14.Moving information in machine tests 
Table1 Parameters of compensation test

\begin{tabular}{lllll}
\hline \multirow{2}{*}{ State } & Time $(\mathrm{min})$ & \multicolumn{2}{l}{ Servo axis } & Spindle \\
\cline { 3 - 4 } State 1 & 10 & Speed $(\mathrm{mm} / \mathrm{min})$ & Range $(\mathrm{mm})$ & Speed $(\mathrm{r} / \mathrm{min})$ \\
State 2 & 10 & 5000 & 10 to 290 & 1000 \\
State 3 & 10 & 6500 & 50 to 290 & 1500 \\
State 4 & 10 & 5000 & 60 to 270 & 2000 \\
State 5 & 10 & 6000 & 30 to 280 & 4000 \\
\hline
\end{tabular}

Table 2. Size errors of actual machining pieces before and after compensation

\begin{tabular}{lll}
\hline \multirow{2}{*}{ Test samples } & \multicolumn{1}{c}{$\Delta Z /(\mathrm{mm})$} & \\
\cline { 2 - 3 } & Comp.off & Comp.on \\
Holes 13 and 14 & -0.009 & -0.001 \\
Holes 15 and 16 & -0.005 & 0.002 \\
Holes 17 and 18 & -0.007 & -0.001 \\
Holes 19 and 20 & -0.010 & 0.001 \\
\hline
\end{tabular}




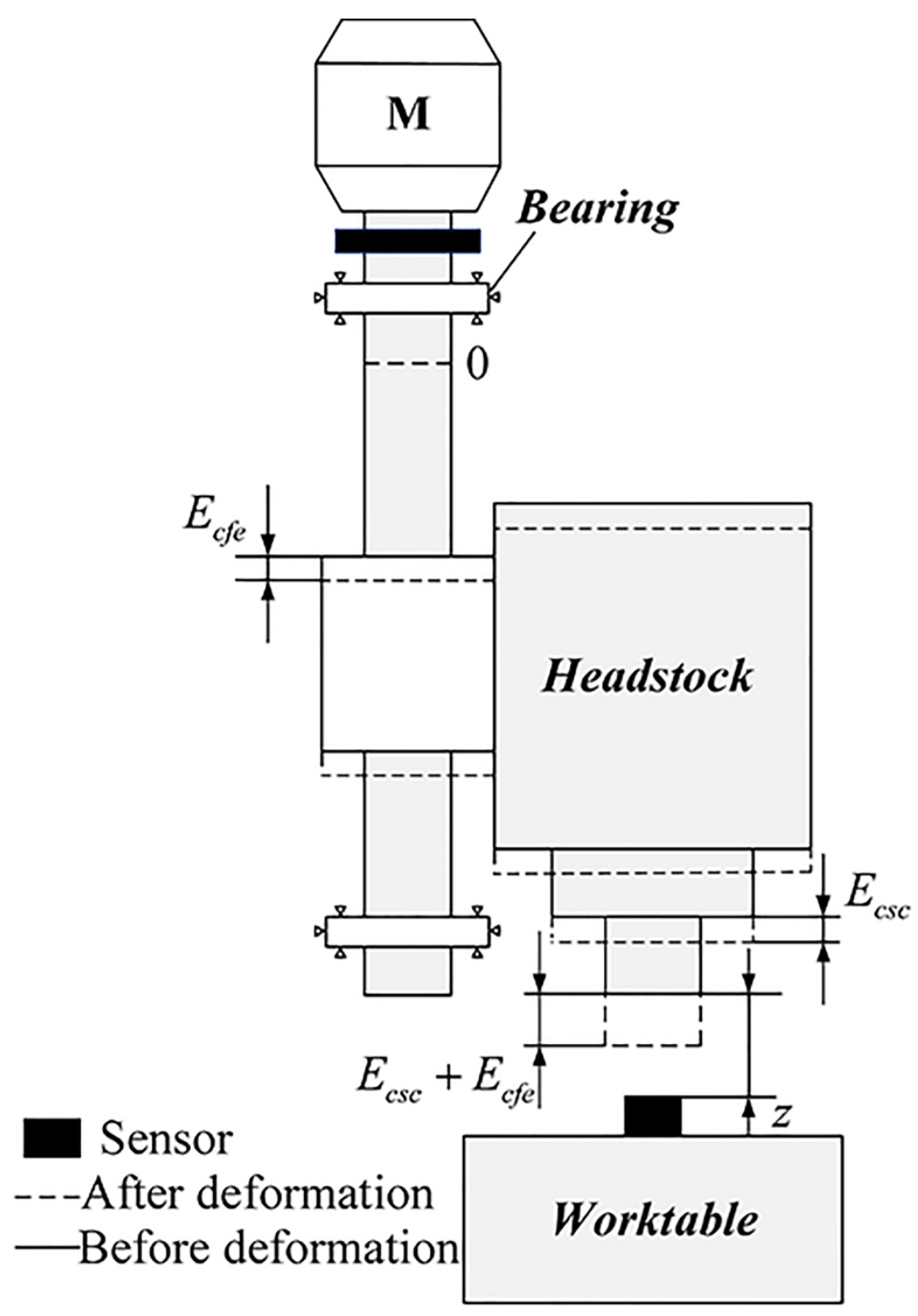

$129 \times 182 \mathrm{~mm}(300 \times 300 \mathrm{DPI})$ 


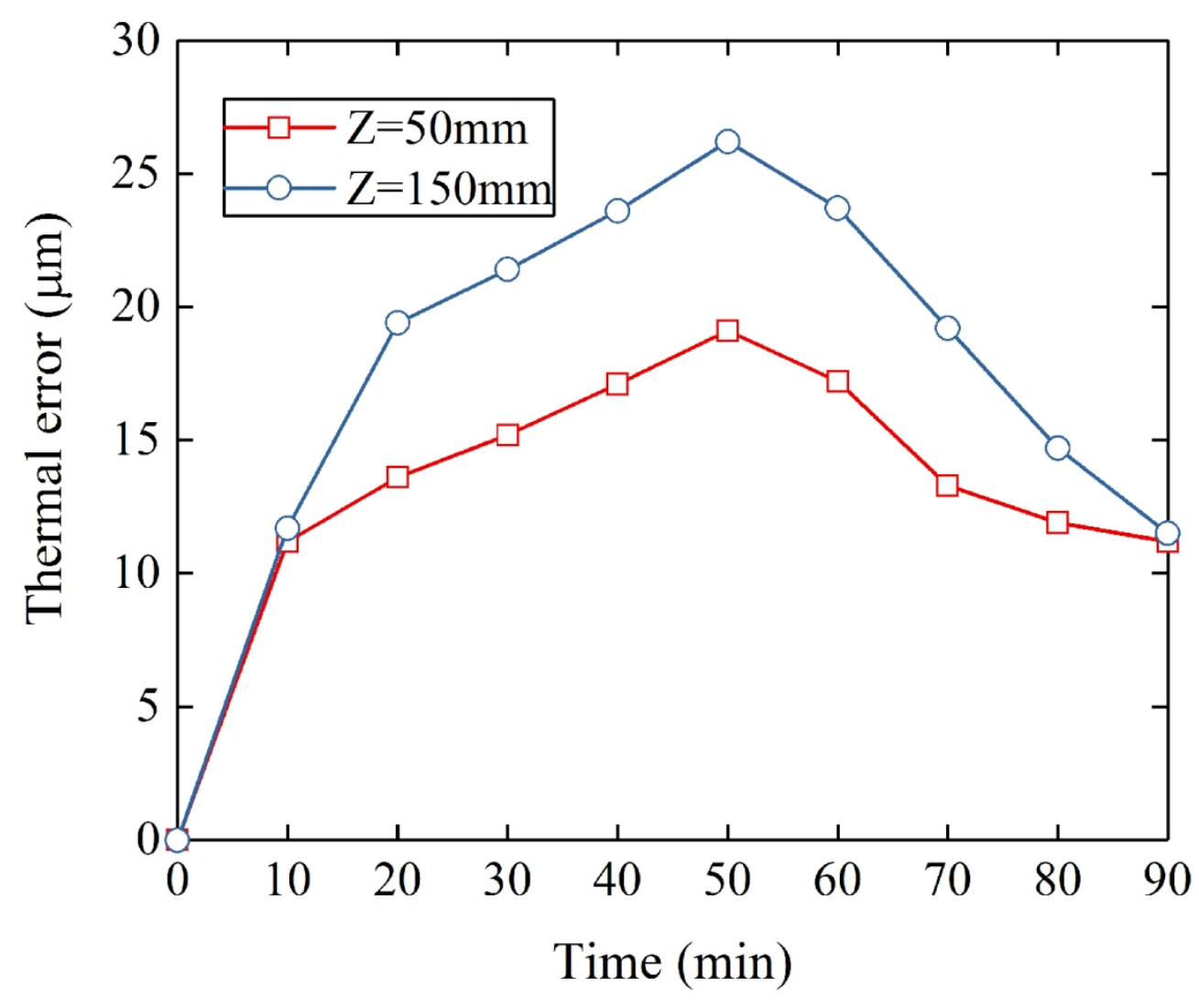

$129 \times 107 \mathrm{~mm}(300 \times 300$ DPI $)$ 


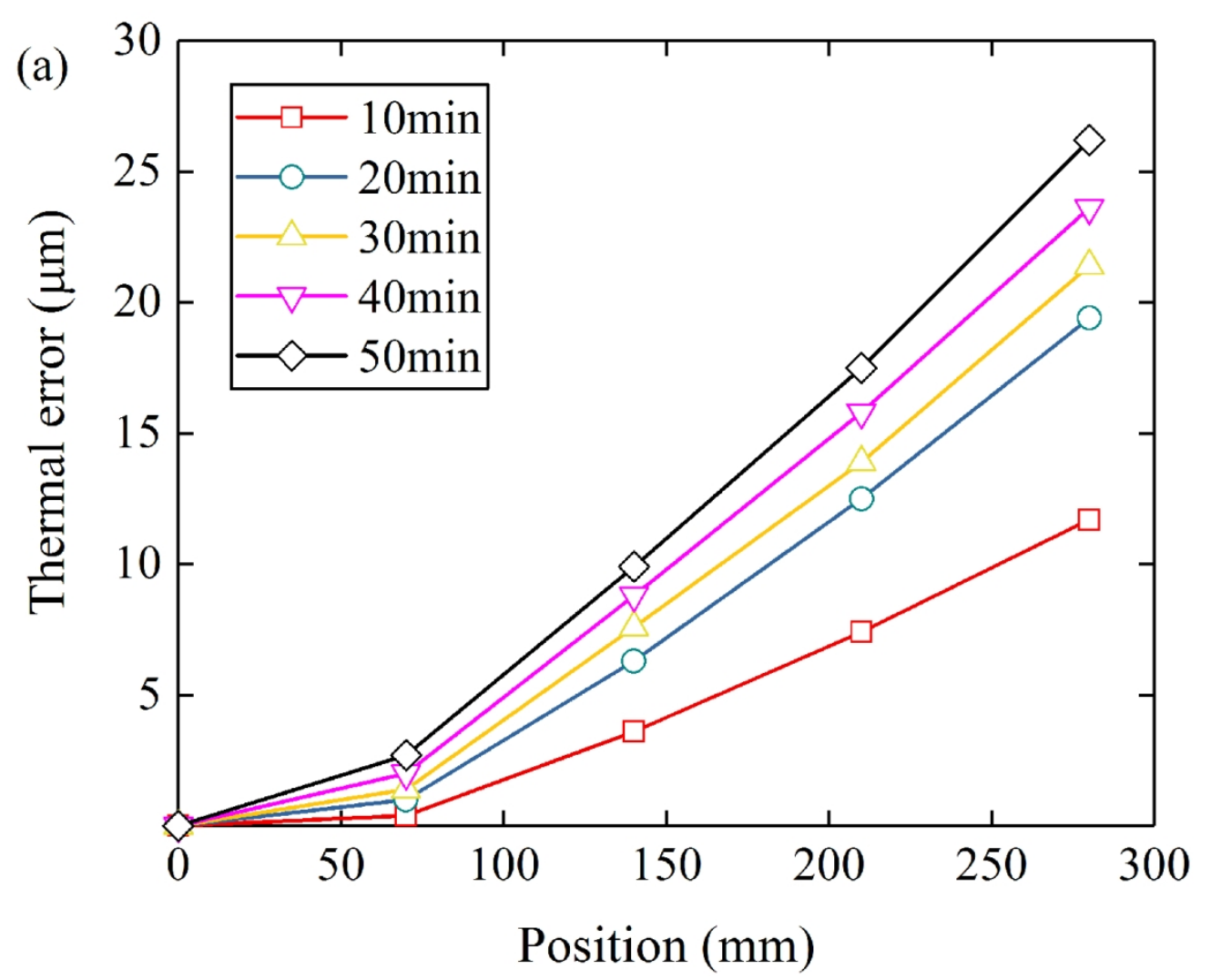

$129 \times 106 \mathrm{~mm}(300 \times 300 \mathrm{DPI})$ 


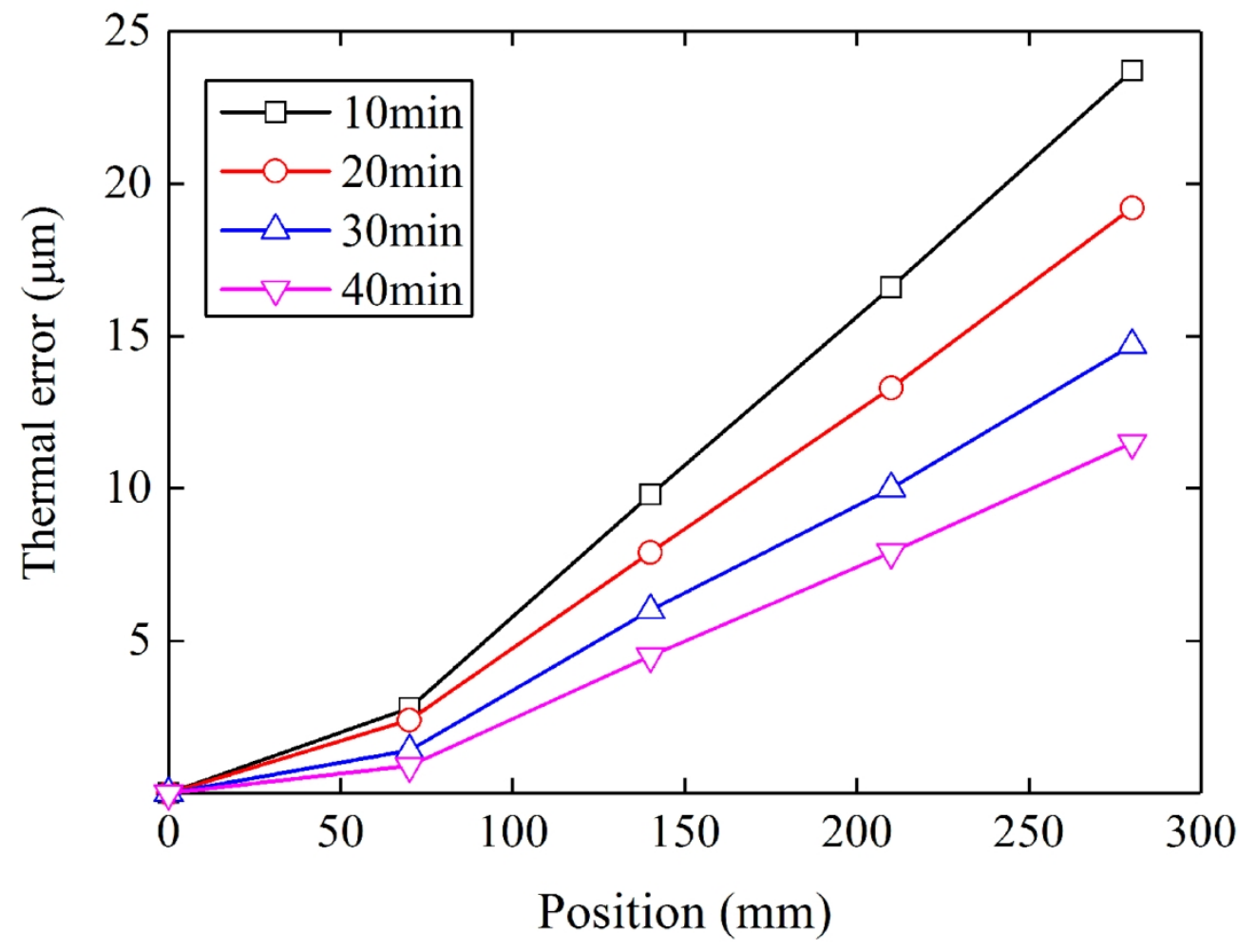

$129 \times 98 \mathrm{~mm}(300 \times 300 \mathrm{DPI})$ 


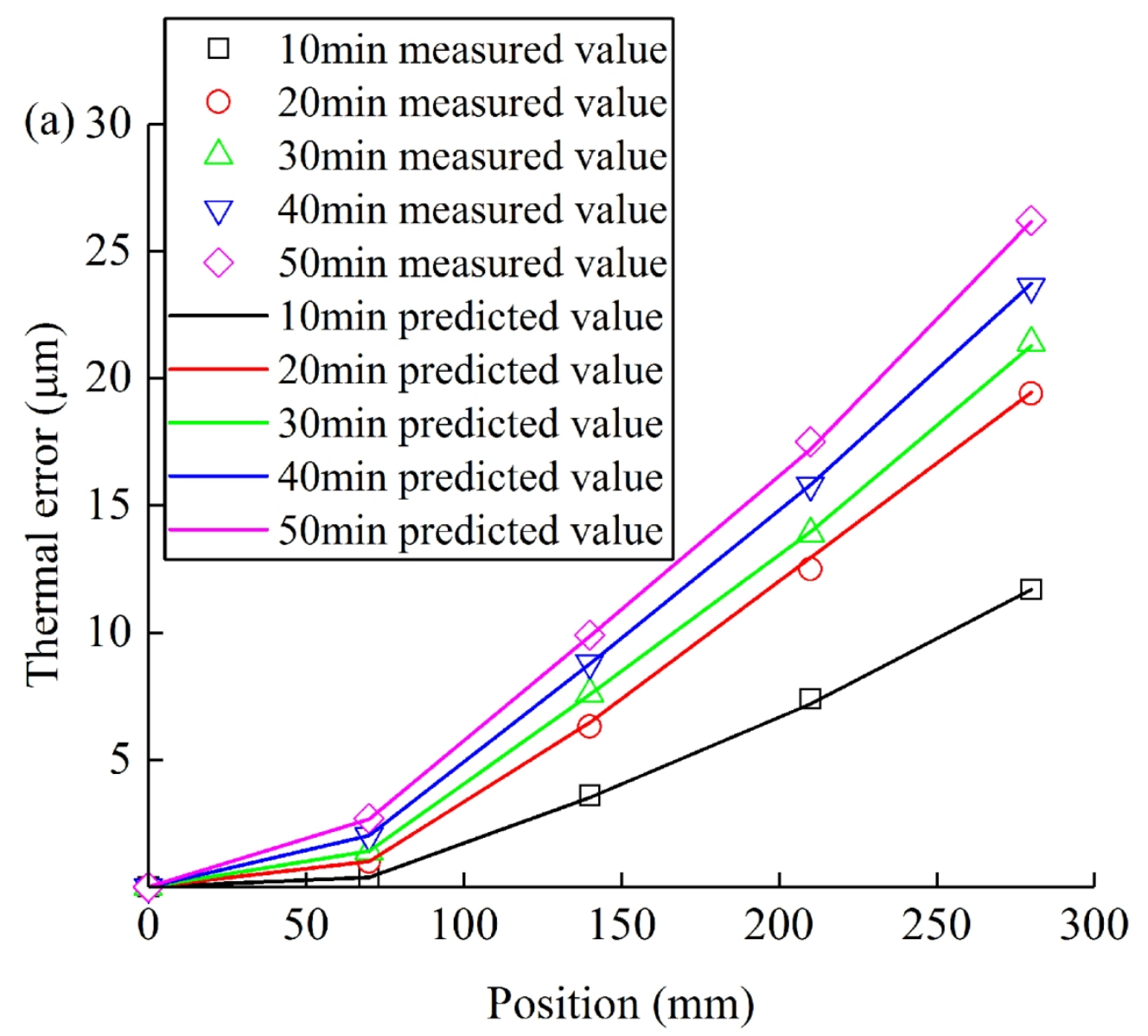

$129 \times 117 \mathrm{~mm}(300 \times 300 \mathrm{DPI})$ 


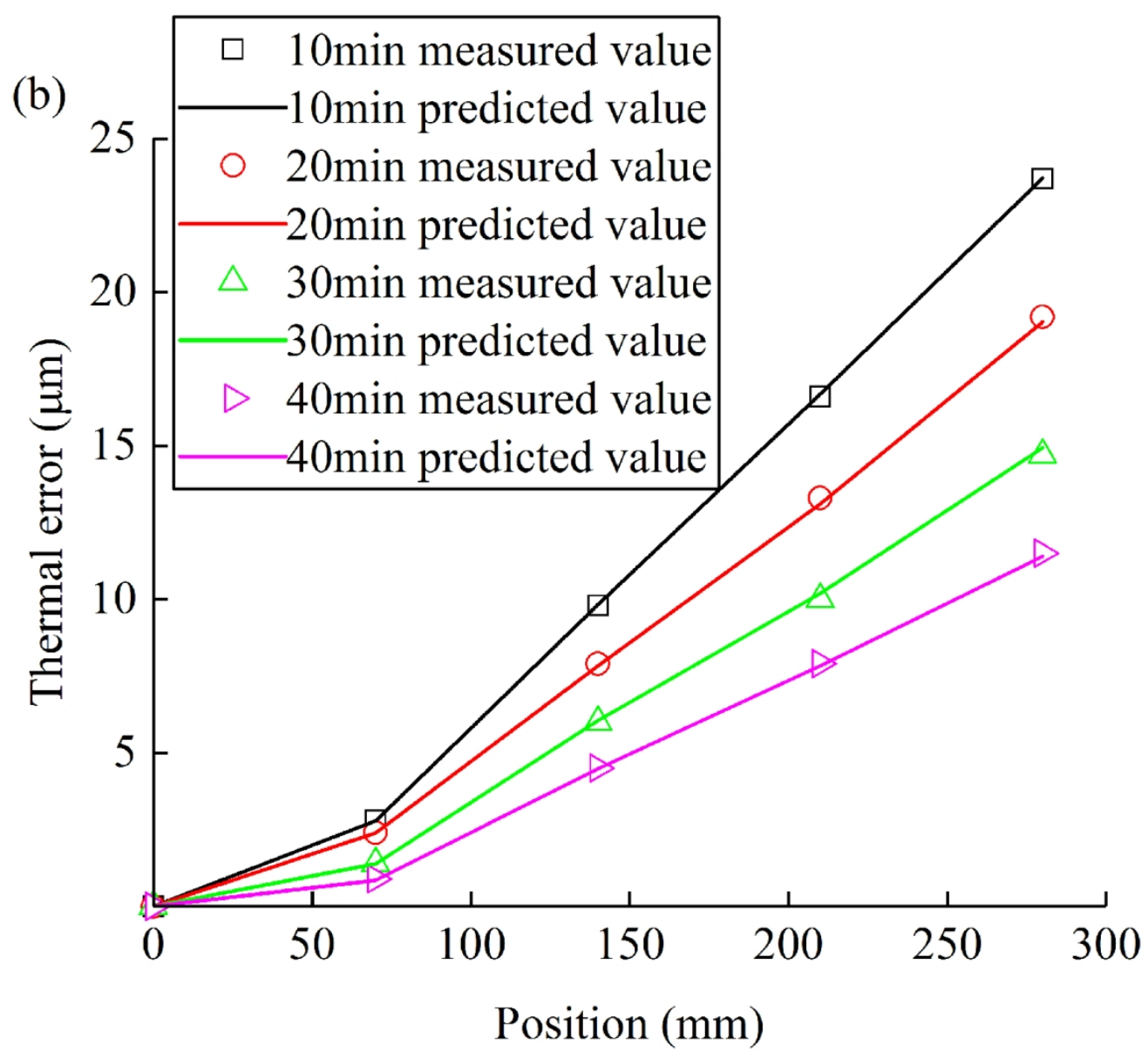

$129 \times 118 \mathrm{~mm}(300 \times 300$ DPI $)$ 


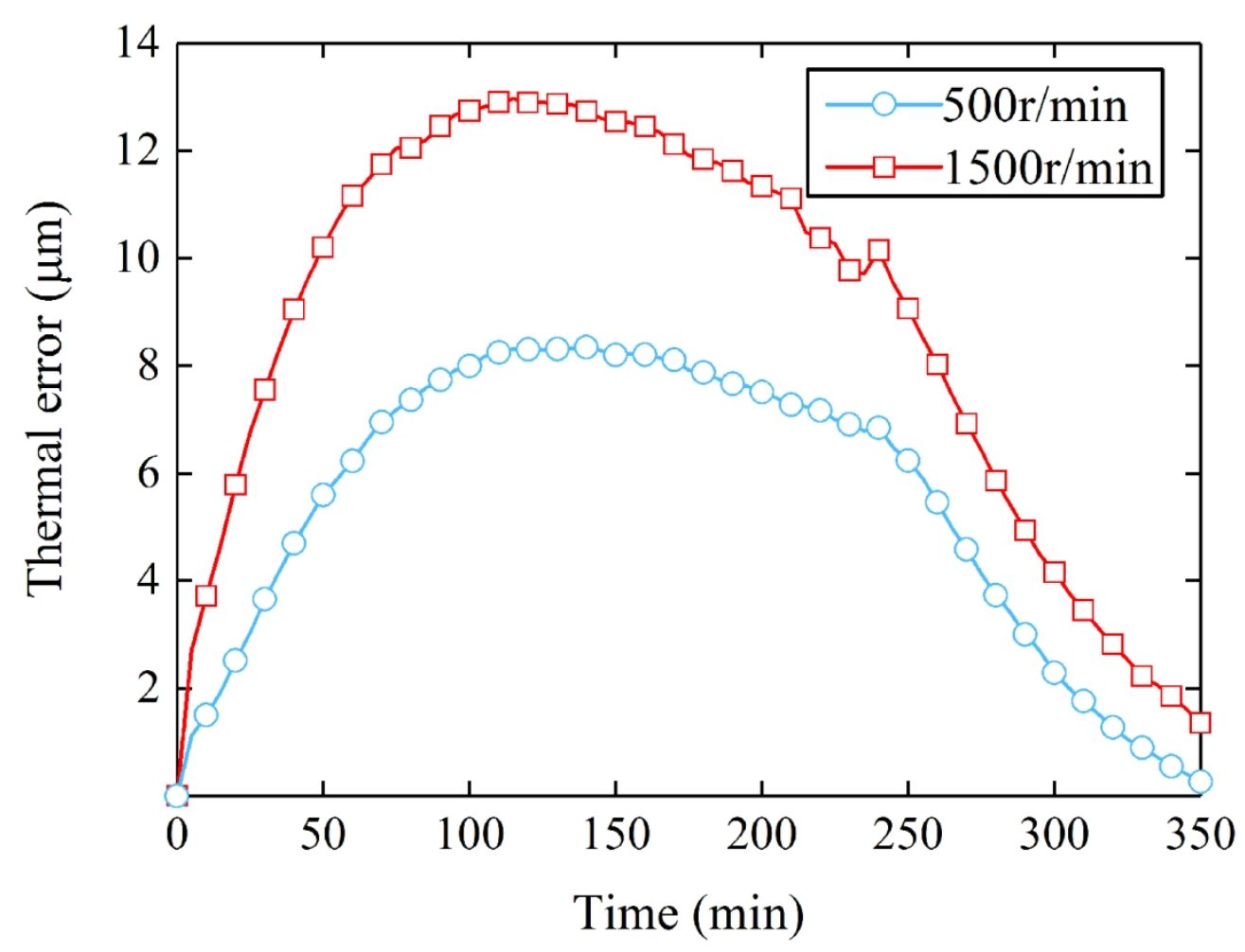

$129 \times 98 \mathrm{~mm}(300 \times 300$ DPI $)$ 


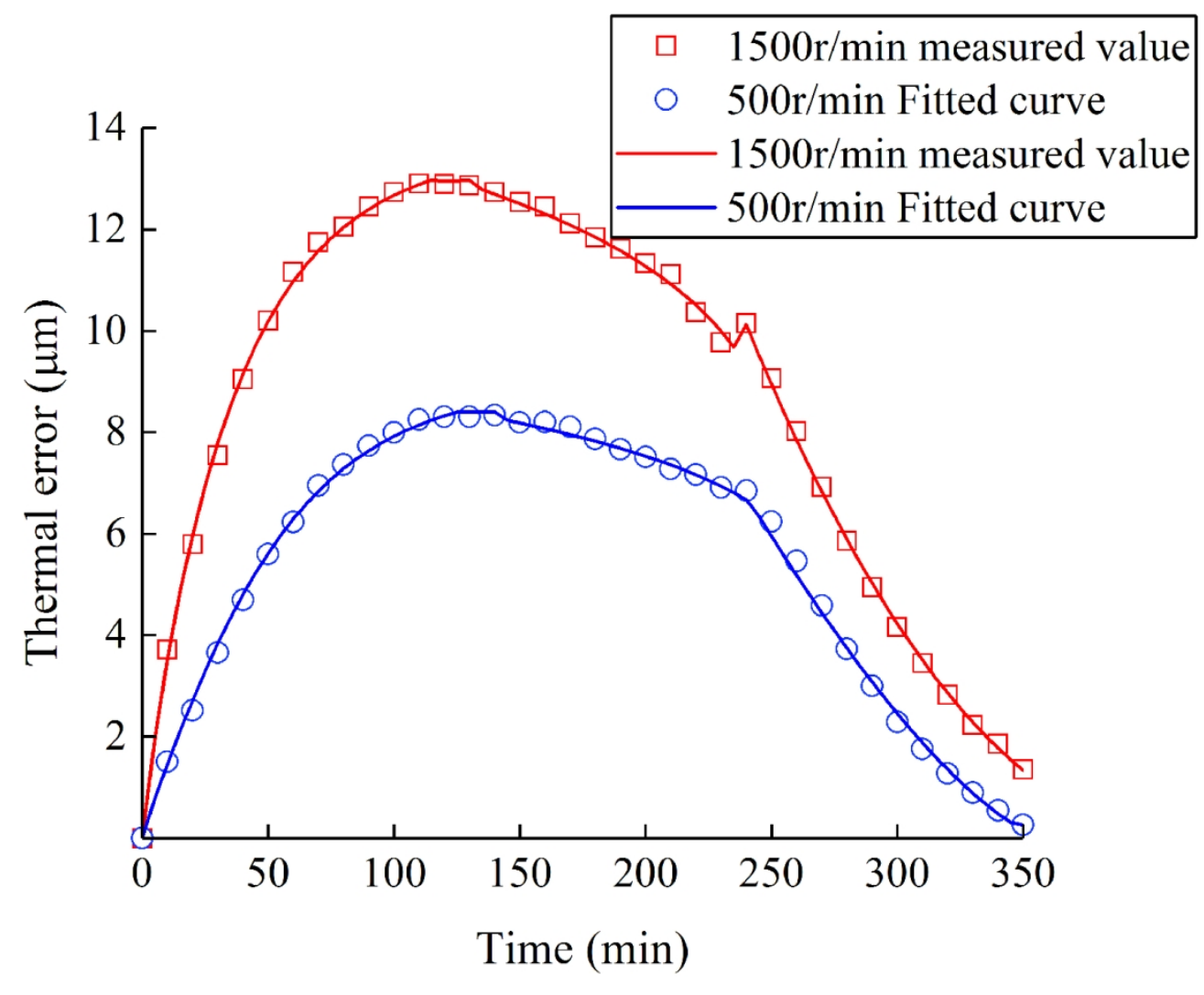

$129 \times 104 \mathrm{~mm}(300 \times 300$ DPI) 


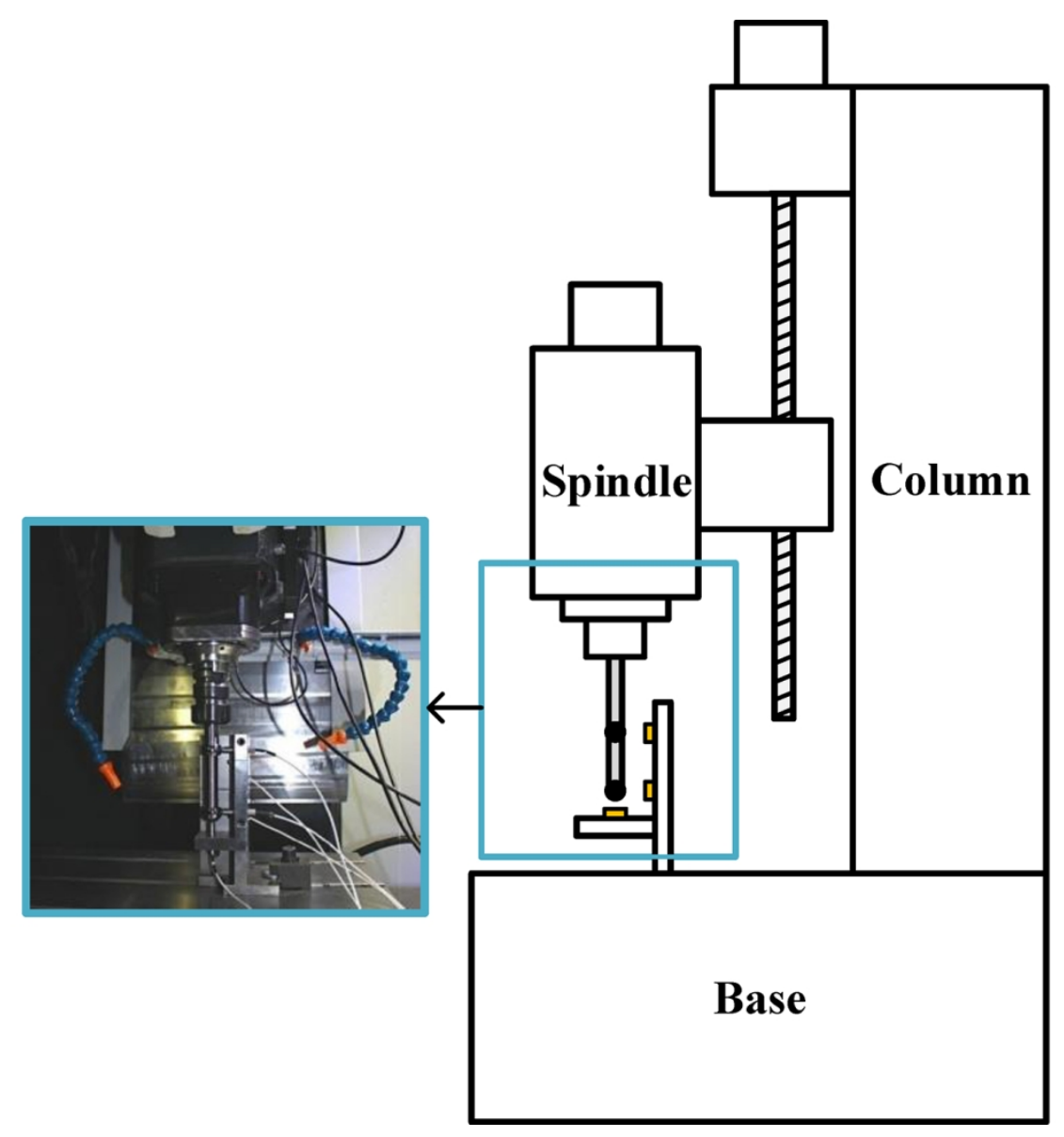

$129 \times 117 \mathrm{~mm}(300 \times 300 \mathrm{DPI})$ 


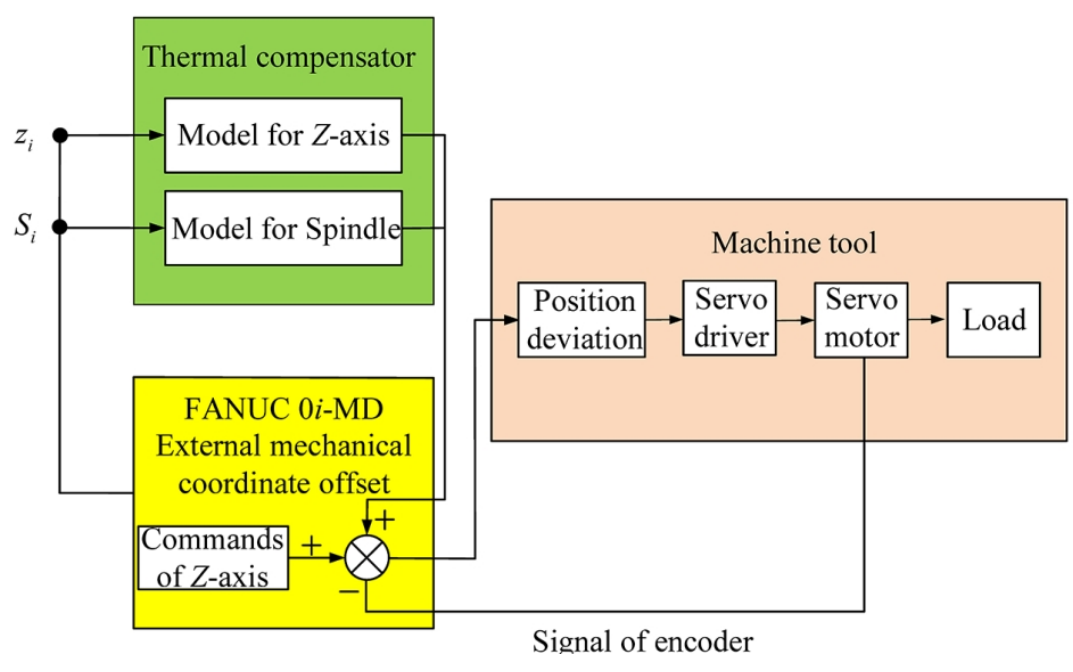

$129 \times 65 \mathrm{~mm}(300 \times 300$ DPI $)$ 


\section{CNC Compensation interface}

\section{Configuration}

CNC IP address: 192.168 .1 .1 Threshold value: 100 Save file path: D:lerror CNC Communication: OK

\section{Monitoring}

Tool X-axis position( $\mathrm{mm})$ :

Tool Y-axis position(mm):

Tool Z-axis position( $\mathrm{mm})$ :

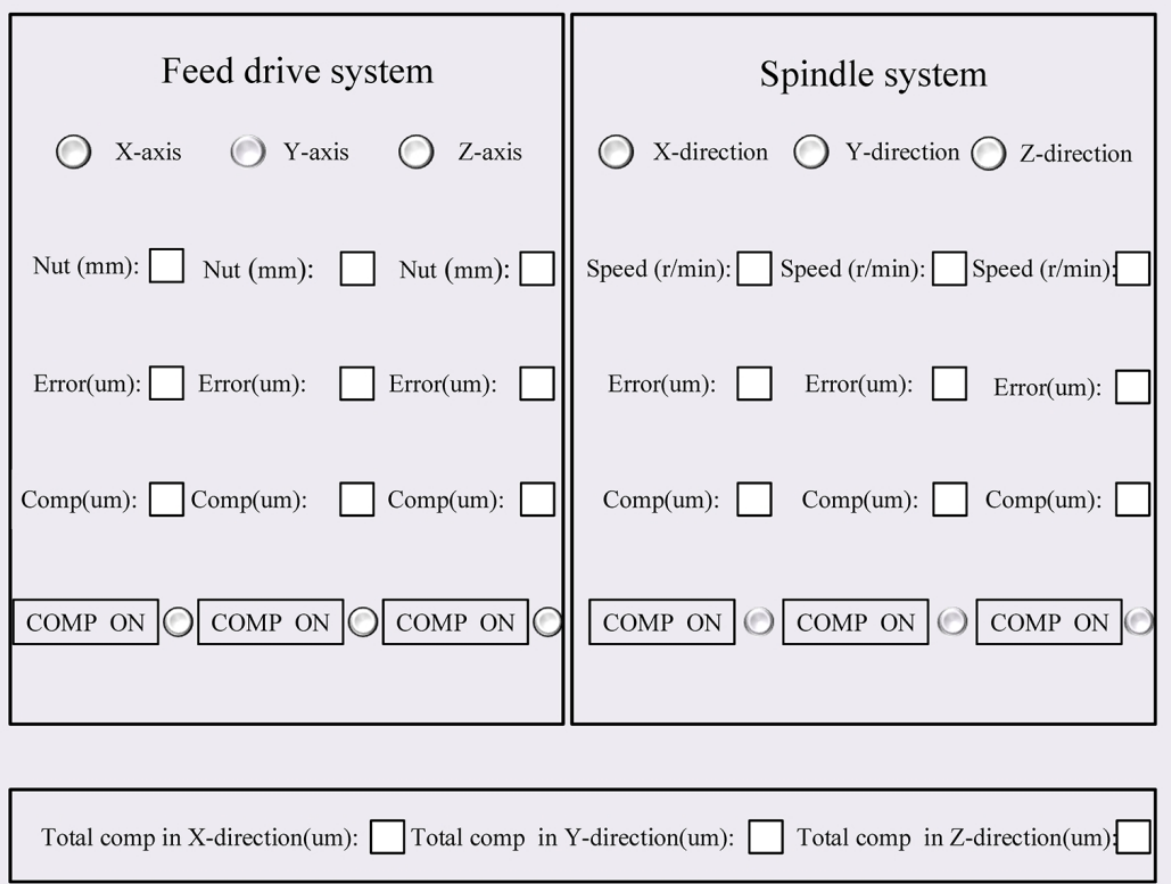




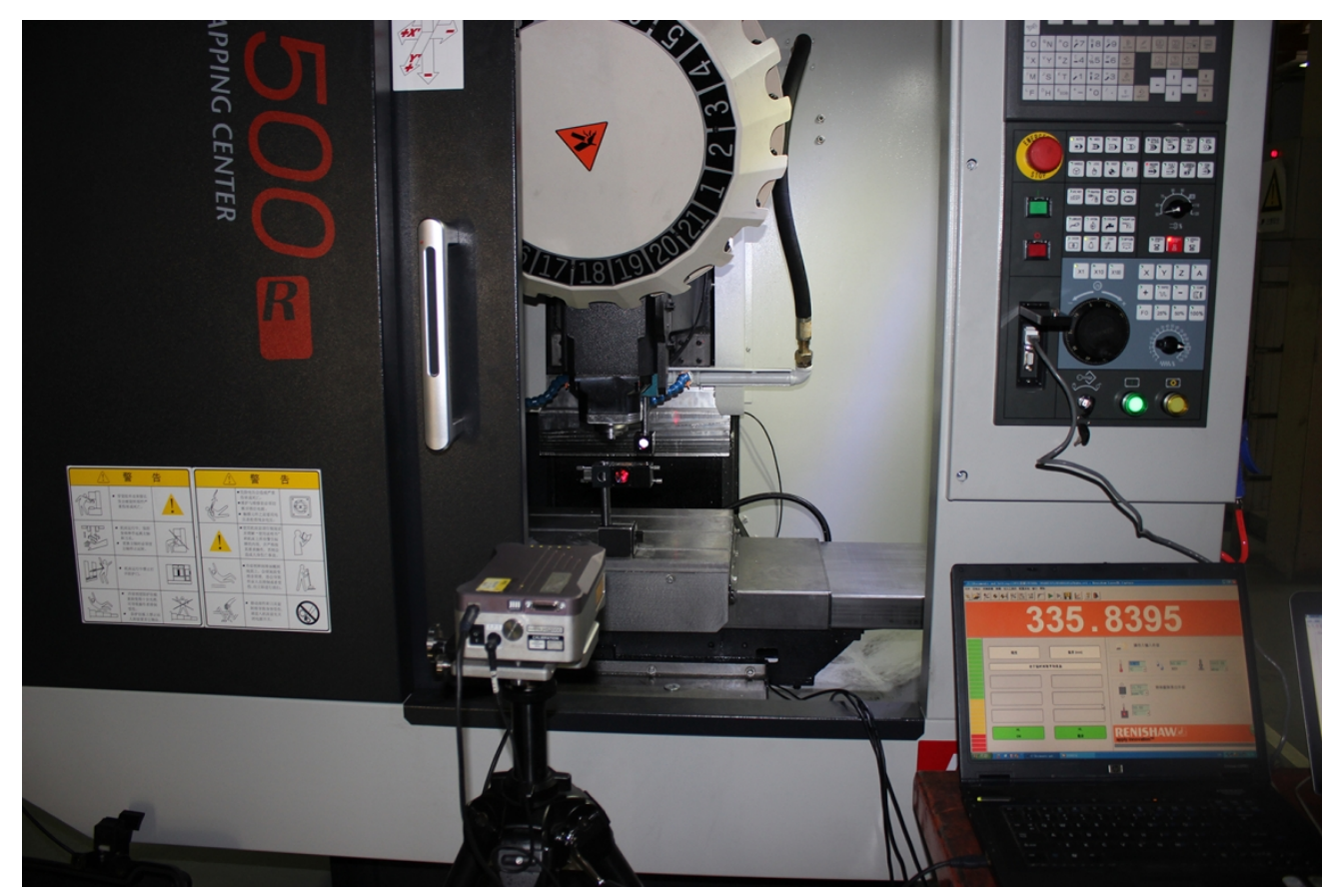

$129 \times 86 \mathrm{~mm}(300 \times 300 \mathrm{DPI})$ 


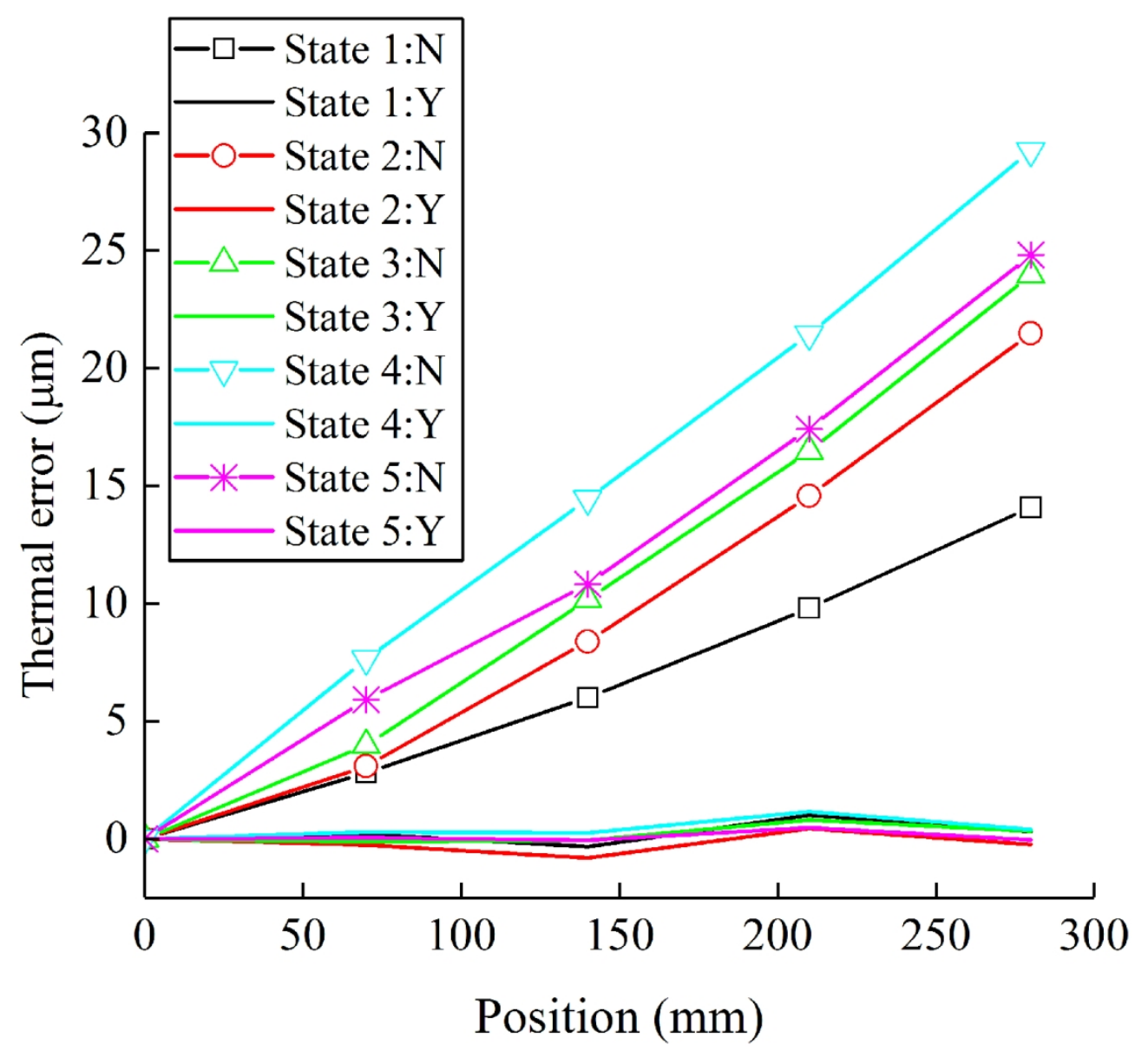

$129 \times 118 \mathrm{~mm}(300 \times 300 \mathrm{DPI})$ 


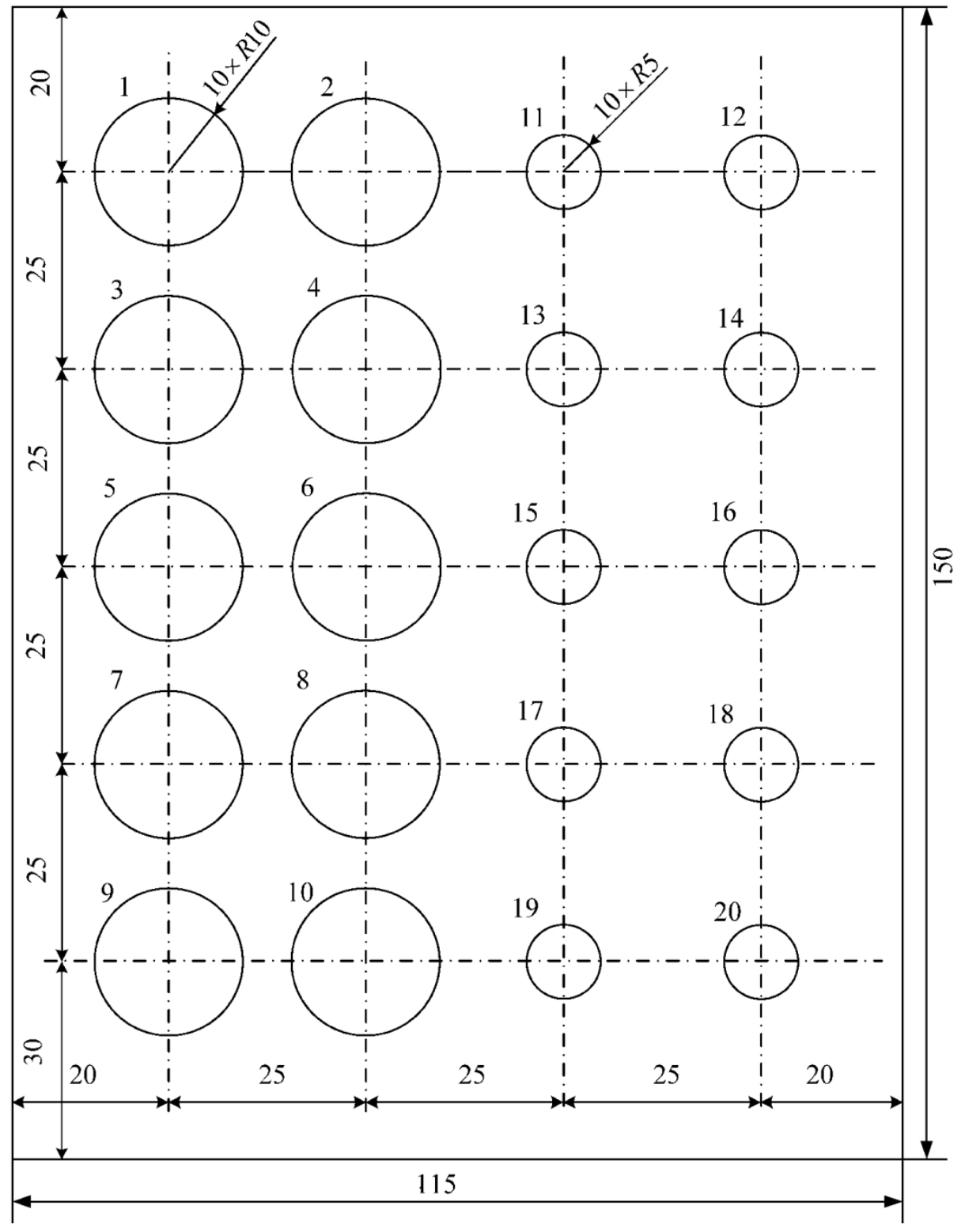

$129 \times 162 \mathrm{~mm}(300 \times 300 \mathrm{DPI})$ 
(a)

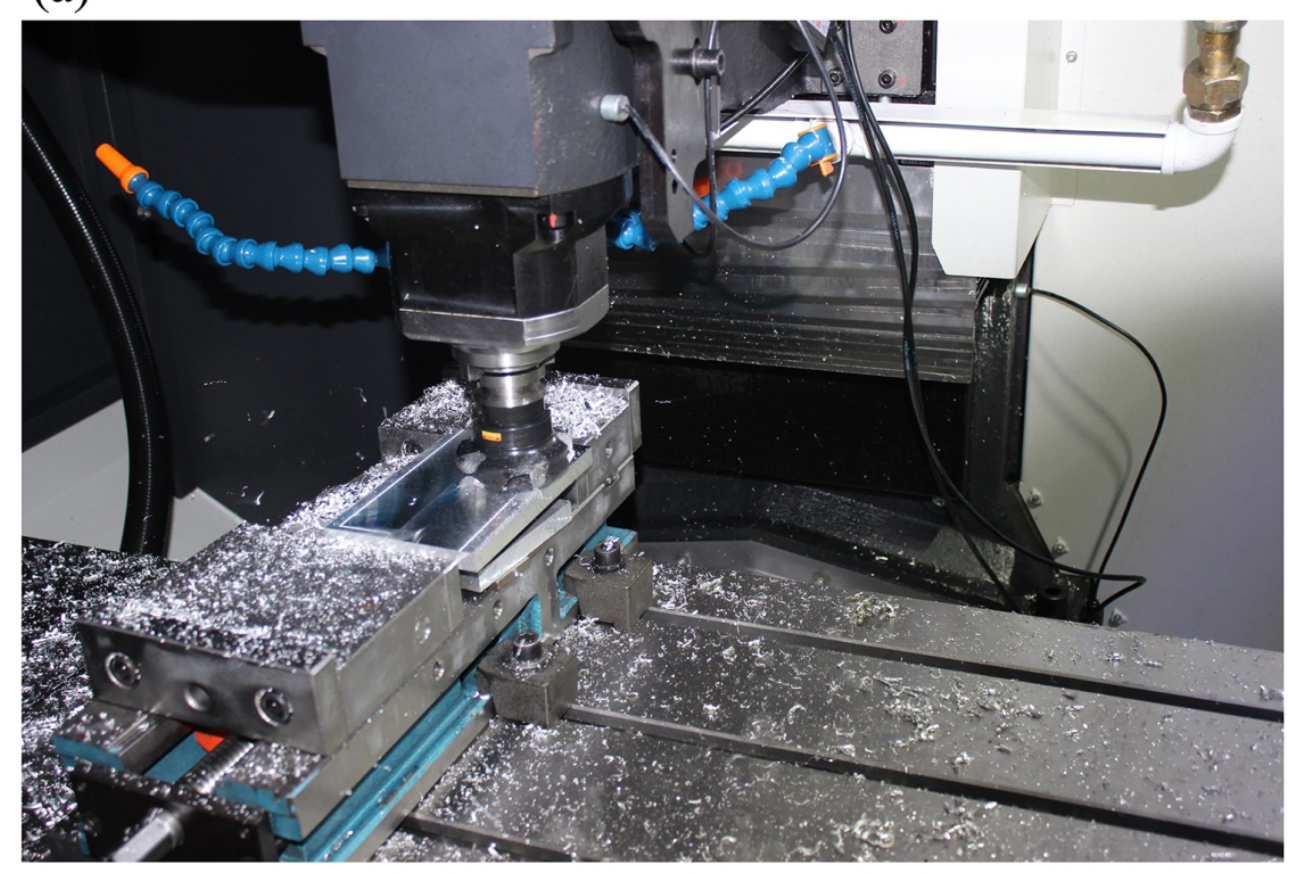

$129 \times 94 \mathrm{~mm}(300 \times 300$ DPI $)$ 


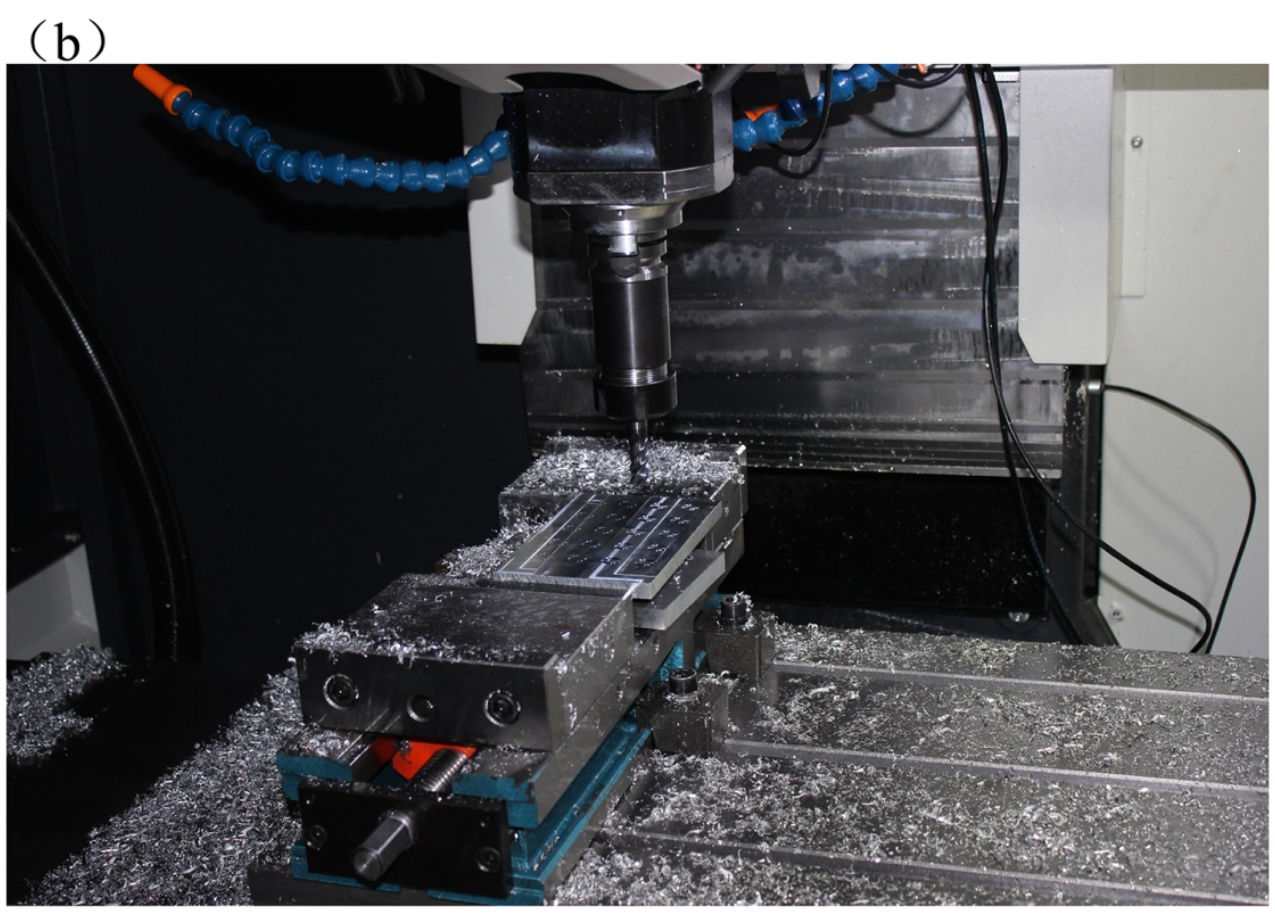

$129 \times 94 \mathrm{~mm}(300 \times 300 \mathrm{DPI})$ 


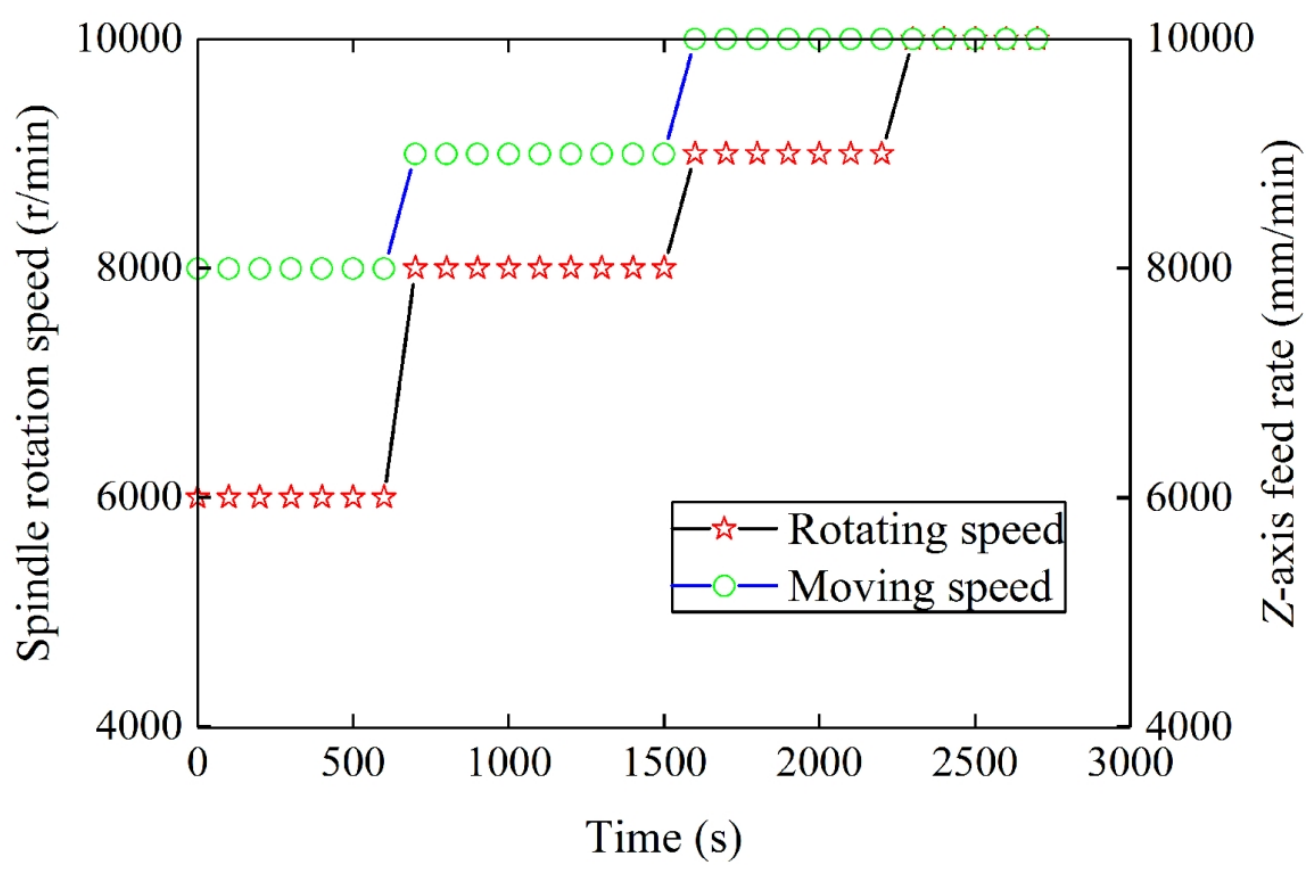

$129 \times 85 \mathrm{~mm}(300 \times 300$ DPI $)$ 


\section{Appendix}

\section{Nomenclature}
$E_{c s e}$
Spindle position displacement value
$E_{c f e}$
Ball screw position displacement value
$\zeta_{\text {screw }}(T)$
Ball screw thermal expansion model curve
$Q_{\mathrm{e}}$
Ball screw displacement caused by heat generation
$Q_{\text {r }}$
Ball screw displacement caused by heat dissipation
V
Average moving speed
C
Average moving frequency
$z_{j}$
Current position of screw axis
$\lambda$
Heat production coefficient of screw
$r, s$
Coefficient of exponential model about heat production
$K$
Number of data with moving speed at the sampling time
$N$
Total number of screw position at the sampling time
$\kappa$
Heat dissipation coefficient of screw
$h$
Coefficient of exponential model about heat dissipation
Time
$\zeta_{\text {screw }}\left(t_{b}\right)$
Screw initial error in the cooldown phase
$\delta_{\text {spindle }}(t)$
Spindle thermal growth model curve
$Q_{\text {spindle }}$
Spindle displacement due to heat generation 
$q_{\text {spindle }}$

$S_{i}$

$\Delta T$

$\alpha$

w

$\eta$

$\varepsilon$

$\delta_{\text {spindle }}\left(t_{a}\right)$
Spindle displacement due to heat dissipation

Spindle rotation speed

Sampling time for measured data

Heat generation coefficient of spindle

Coefficient of exponential model about heat generation

Heat dissipation coefficient of spindle

Coefficient of exponential model about heat dissipation

Spindle initial error in the cooldown phase 